\title{
Research on the integration of ideological and political education into the curriculum design of landscape architecture
}

\author{
Lin Ma ${ }^{1,2}$, Junxia Zhang ${ }^{1,2}$, Yanyan $\mathrm{Jia}^{1,2}$, and Bing $\mathrm{Liu}^{1,2, *}$ \\ ${ }^{1}$ Shandong Provincial Research Center of Demonstration Engineering Technology for Urban and Rural Landscape, 271018Tai'an, China \\ ${ }^{2}$ College of Forestry, Shandong Agricultural University, 271018Tai'an, China
}

\begin{abstract}
The ideological and political construction of curriculum is the inevitable requirement to improve the quality of forestry talent training. The concrete contents of ideological and political teaching design including teaching goal, teaching method, teaching content design, teaching characteristics and teaching summary are expounded and three aspects of further optimization are put forward. Taking the ideological and political construction of the curriculum as an opportunity, based on the professional characteristics and discipline development, it provides reference for the ideological and political construction of the landscape architecture specialty curriculum.
\end{abstract}

\section{Introduction}

Forestry education is the research and management of natural resources related to forest environment, including water resources, wood, fish and wildlife, plants and soil. Forests have many advantages in the environment. They not only provide beauty and entertainment throughout the year, but they also provide economic production through timber and wildlife habitats. It's important to maintain these resources. Forestry protection has become an important part of forestry education. Issues in the field of conservation include deforestation, biodiversity and human impacts, and interactions within forests. Forestry education helps to ensure that forests are managed in an ecologically sound way. Future forestry technicians will learn how to improve and protect the forest environment. They also learn how to improve and maintain good water conditions. Forestry includes the management and development of forests. In addition, forestry education enables students to learn how to find better ways to obtain wood for use in homes and buildings. Forestry education also teaches about climate change and its impact on forests. Forest management education covers all aspects of environmental protection and recovery, as well as health maintenance, research and product development and fire risk reduction.

By the end of 2020, there are only 18 papers about Landscape Architecture education. Based on the professional characteristics, how to excavate the humanistic spirit and value significance deep under the surface symbols of landscape architecture knowledge, in the explanation of principles and the teaching of knowledge, externalize the spirit and value into teaching practice and internalize it into the spiritual cultivation and value pursuit of students, so as to truly achieve the goal of carrying the soul of Ideological and Political
Education in the body of professional courses, and promote the collaborative development of the two[1,2]. It is an important task for landscape architecture education in the new era to implement the whole process and all-round of classroom teaching.

Scenic area planning is a compulsory course which involves the connotation of scenic spots and the basic principles, methods and techniques of planning. The course takes scenic spots as the research object, and scenic spots contain rich natural landscape and cultural landscape [3]. Its construction and development are closely related to the times, so the course has good conditions for ideological and political construction [4]. Since the establishment of the system of scenic spots in 1982, the cause of scenic spots in China has made great progress. Scenic spots protect the most precious geological relics, the most typical geomorphic types and the most beautiful natural landscape, and make positive contributions to the protection of biodiversity in China and the world; inherit rich national culture, and preserve a large number of cultural heritage in the form of material or non-material carriers; pay attention to the harmonious unity of nature and culture, and protect the nature and people where traditional culture is located as a whole Cultural environment makes traditional culture a living and inheritable culture, and makes an important contribution to the inheritance of Chinese culture and global civilization [5]. These ideological and political elements are the basis for carrying out the ideological and political construction of the course. Fully excavating the ideological and political elements contained in the course and integrating with the characteristics of the times will help to realize the organic unity of knowledge teaching and value guidance of the course Scenic Area Planning [6].

\footnotetext{
"Corresponding author: lbcta@126.com
} 


\section{Project design and methods}

This paper expounds the specific content of Ideological and political teaching design from five aspects: teaching objectives, teaching methods, teaching content design, teaching characteristics and teaching summary.

\subsection{Objectives}

The objective is to master the classification method of scenic resources (2 major categories, 8 medium categories and 78 sub categories) in the master planning standard for scenic spots (GB 50298-2018).

On the basis of theoretical explanation, through the preliminary investigation and classroom classification of the landscape resources of Nanjing Zhongshan scenic spot, students are guided to deeply explore the natural characteristics, artistic charm, scientific value, historical details and cultural connotation of the landscape resources, so as to promote students to love the beautiful rivers and mountains of the motherland and the splendid history and culture, and then encourage them to use the professional knowledge of landscape architecture, Painting beautiful mountains and rivers, make up beautiful mountains and rivers, live up to the time, seize the day and contribute to the construction of beautiful China!

\subsection{Design and methods}

The content design includes two parts: the classification of scenic resources in national standards and the explanation of the meaning of key sub categories.

\subsubsection{The combination of pre class preview and classroom teaching}

Through the assignment of theory preview and case investigation (Zhongshan Scenic Area in Nanjing) in advance, the students can have a general understanding of the teaching content of this lesson. Classroom teaching is mainly based on five knowledge points, such as classification method, which is not only the key point but also the difficulty, but also the main line running through pre class preview and classroom explanation.

\subsubsection{Combining theory introduction with case analysis}

The theoretical part of this lesson mainly introduces the classification method of landscape resources in the general planning standard for scenic areas (GB50298-2018). However, the classification methods are numerous and small. It is difficult to distinguish the meanings of some small categories. Therefore, a case study and theoretical introduction are applied to take the scenic spots of Zijin Mountain in Nanjing as an example. It is divided into the corresponding sub categories, which really realizes the close combination of theory and practice.

\subsubsection{The combination of concentrated explanation in class and group discussion after class}

The theoretical introduction and case analysis of this class adopt the way of concentrated explanation in class. At the end of the class, group discussion assignments are arranged for the names of several other categories whose meanings are difficult to distinguish. The discussion results will be reported in groups in the next class. Students not only deepen their mastery of each knowledge point, but also give full play to their enthusiasm and initiative.

\section{Results}

This paper selects the first section of landscape resources classification in the second chapter of landscape resources investigation and evaluation, including the classification of scenic resources and the explanation of the meaning of key sub categories, mainly including the following five design results.

\subsection{Classification method of scenic resources}

The classification method of scenic resources in the standard for master planning of scenic spots (GB 50298-2018) is divided into 2 major categories (natural scenery and human scenery), 8 medium categories (sky, ground, water, living, garden, architecture, scenic spots and scenery) and $78 \mathrm{sub}$ categories. It is required to divide each single scenic resource into a certain sub category, and some sub categories contain. Ideological and political elements: love the motherland's rich natural landscape resources and profound historical and cultural connotation.

The specific contents are as follows: through the introduction and classification of the landscape resources of Nanjing Zhongshan scenic spot, the students deeply realize that China's natural landscape resources are magnificent and diverse, and the human landscape resources have a long history and far-reaching connotation, both of which are full of the wisdom and sweat of the working people, and contain deep patriotism. The protection of scenic spots should not only protect its material entity, but also protect its cultural essence, that is, to plant patriotism in the heart and pass on the belief of patriotism from generation to generation.

\subsection{Categories of landscape}

There are 9 sub categories of landscape, including famous historical garden, modern park, botanical garden, zoo, courtyard garden, special garden, tomb garden, recreation and Sports Park, and other landscape. Ideological and political elements: learning Dr. Sun Yat Sen's patriotism, revolutionary will and enterprising spirit.

The specific contents are as follows: select Zhongshan Mausoleum, a typical tomb altar cemetery in Zhongshan scenic spot, so that students can deeply understand its spiritual connotation on the basis of 
understanding its historical development and features of scenery composition, that is, Zhongshan Mausoleum is the mausoleum of Sun Yat Sen, the great forerunner of democratic revolution, whose "three people's principles" and "fraternity" ideas inspire generation after generation We should remember Dr. Sun Yat Sen's historical contributions to national independence, social progress and people's happiness, and study, inherit and carry forward his patriotism, revolutionary will and enterprising spirit.

\subsection{Categories of architecture}

In architecture, there are 12 sub categories, including landscape architecture, ancestral hall, religious architecture, palace office, memorial architecture, cultural and entertainment architecture, commercial architecture, industrial and traffic architecture, engineering structure, characteristic village, characteristic block, and other buildings. The elements of thinking and politics are: protecting our architectural heritage and inheriting the essence of craftsmen's wisdom.

The specific contents are as follows: select the music stage in Zhongshan Scenic Area as a typical memorial building, on the basis of introducing its construction history and layout form, deeply analyze the western architectural style, that is, fully absorb the characteristics of ancient Greek architecture, and adopt the expression form of Chinese Jiangnan classical garden, so as to achieve the perfect unity of nature and architecture. Broad and profound art beats nature. Skilled craftsmen and wise artists are the best and most intelligent architects. We should protect and inherit and develop the spirit of the great minds.

\subsection{Categories of famous sites}

There are eight sub categories of famous sites, including ruins, cliff inscriptions, grottoes, sculptures, monuments, science and technology projects, recreational and sports venues, and other famous sites.

The specific contents are as follows: select the typical memorial site of Nanjing aviation Martyrs Memorial Hall in Zhongshan scenic area, on the basis of introducing its layout and heroic deeds, lead the students to pay homage to the martyrs.

\subsection{Categories of scenery}

There are 9 sub categories of scenery, including festivals and holidays, national customs, religious rituals, myths and legends, folk literature and art, local figures, local products, folk skills, and other scenery. Ideological and political elements: perseverance, hard work to harvest success.

The specific contents are as follows: select the typical folk custom sub category of "Nanjing International Plum Blossom Festival", which is held every spring in Zhongshan scenic area. On the basis of introducing the history of planting and appreciating plum blossoms in Nanjing and the main ornamental varieties of plum blossoms, associate the reputation of "three friends in the cold of the year" and the character of "plum blossom fragrance comes from the bitter cold", guide the students not to rush when they encounter difficulties or setbacks She is impatient, brave to insist, steadfast and willing to work; only when she is not afraid of difficulties and dangers, can she "smile in the bush when the mountain flowers are blooming".

\section{Summary}

In the teaching design of this course, there are three links: preview before class, classroom teaching and after class discussion. Students can master the classification method of scenic resources in the master planning standard for scenic spots (GB 50298-2018), and make clear the meaning of several key sub categories; they can classify the landscape resources of a given object according to the master planning standard for scenic spots (GB 50298-2018) It can stimulate students' deeper love for the motherland and turn this love into professional knowledge learning and practical action of building a beautiful China. The knowledge goal, ability goal and ideological and political teaching goal of this lesson have been achieved, and the teaching feedback is good.

\section{Future prospects}

Combined with the specific teaching content of scenic area planning course, this study integrates the ideological and political elements such as patriotism, sense of hardship, cultural heritage, enterprising spirit in the form of case analysis, with a variety of types, which has certain representativeness and era significance. In the future, we can further optimize the teaching design from the following three aspects:

(1) On the basis of solid literature research and social investigation, the next goal of the ideological and political design of the course is to guide students to understand the historical changes of social system and the historical achievements of the country from near to far, from the outside to the inside, from the outside to the inside, to strengthen positive guidance, to solve doubts and doubts, and to naturally infiltrate the feelings of home and country into all aspects of the course content.

(2) In the new international and domestic situation, let more, more targeted and timeliness of Ideological and political ideas naturally and deeply into the professional knowledge teaching, let the students really into the ear, into the brain, into the heart, make the effect of Ideological and political education more significant, is the focus of the next step of the ideological and political curriculum design.

(3) According to the characteristics of youth growth, focusing on the ideological concern of youth, focusing on the influence of students' moral quality, making efforts to organically combine the ideological, theoretical, knowledge and the acceptability of teaching methods, and constantly enhancing the affinity and influence of Ideological and political education in curriculum design 
is the direction of the next step of curriculum ideological and political design.

\section{Acknowledgments}

The authors are grateful for the supports of the Second Batch of Collaborative Education Project of Industry University Cooperation of the Ministry of Education in 2019 (201902324005 and 201902211004), Postgraduate Teaching Reform Research Project of Shandong Agricultural University (JYYB2019007), and the Second Batch of Key Teaching Reform Projects of Shandong Agricultural University during the $13^{\text {th }}$ Five Year Plan period (X2019022).

\section{References}

1. Jun Y., Xiaojing Z., Yiqi Z. Xiandai Horticulture, 23,189-191(2020)

2. Weihuang Q. Ideological \& Theoretical Education, 7,10-14(2017)

3. Ministry of Housing and Urban-Rural Development of the People's Republic of China, Development Bulletin of the Chinese Scenic Area(1982-2012), (2012)

4. Daokun L. Ideological \& Theoretical Education,3,64-69(2018)

5. Taoze S., Yongqiang S., Hongna M. Xiandai Horticulture,21,198-200(2020)

6. Xizi L., Jing F. Higher Education Forum, 10,37-39(2020) 